\section{PEDIATRIC OTOLARYNGOLOGY: PRACTICAL CLINICAL MANAGEMENT}

\section{R W Clarke}

Thieme, 2017

ISBN 9783131699015 pp 416 Price $€ 139.95$

$£ 125.00$

It will not have escaped any who might read this forum that it can be a 'one man band'. The snag of course is that, however good the intentions, however positive the assurances, we are all busy folk and promises of book reviews do not always translate into text. The author of this book we all recall trying to avoid at the Royal Society of Medicine, during his time as editor of ENT \& Audiology News. The hearty Gaelic greeting was always followed by a request for a contribution to the next issue, with a deadline of yesterday.

But, at a glance, I knew I would not dare review this book. What if it had proved to be rubbish? I made no friends, decades ago, by pointing out countless errors in a new edition of our standard UK multivolume textbook. This is an authorship of the great and the good in UK paediatric (how the Greeks intended it to be spelt) practice. So, I am really grateful to Kate for giving the subspecialist expert view here. (Thank goodness she liked it.)

You could easily get confused by Thieme's recent output. We saw a book in 2012 (Wetmore et al.) with the same title, but with the addition of 'Principles and Practice Pathways'. In the same year, we had Pediatric Otorhinolaryngology: Diagnosis and Treatment (Licameli et al.), and, only last year, Surgical Pediatric Otolaryngology (Potsic et al.).

Let us see what she thought of this. She got the review back to me within a week and that did impress. If anyone does feel so motivated, and can actually deliver, try: liam.flood@nhs.net.

L M FLOOD Middlesbrough, UK

I always look forward to receiving a request to review a paediatric ENT book, but am usually left disappointed. However, this book is an exception, and I didn't have to go much further than the list of authors to realise that it would be a good read. Edited by Ray Clarke from Alder Hey, and retailing at $£ 125.00$, this text should be on all trainees' shelves.

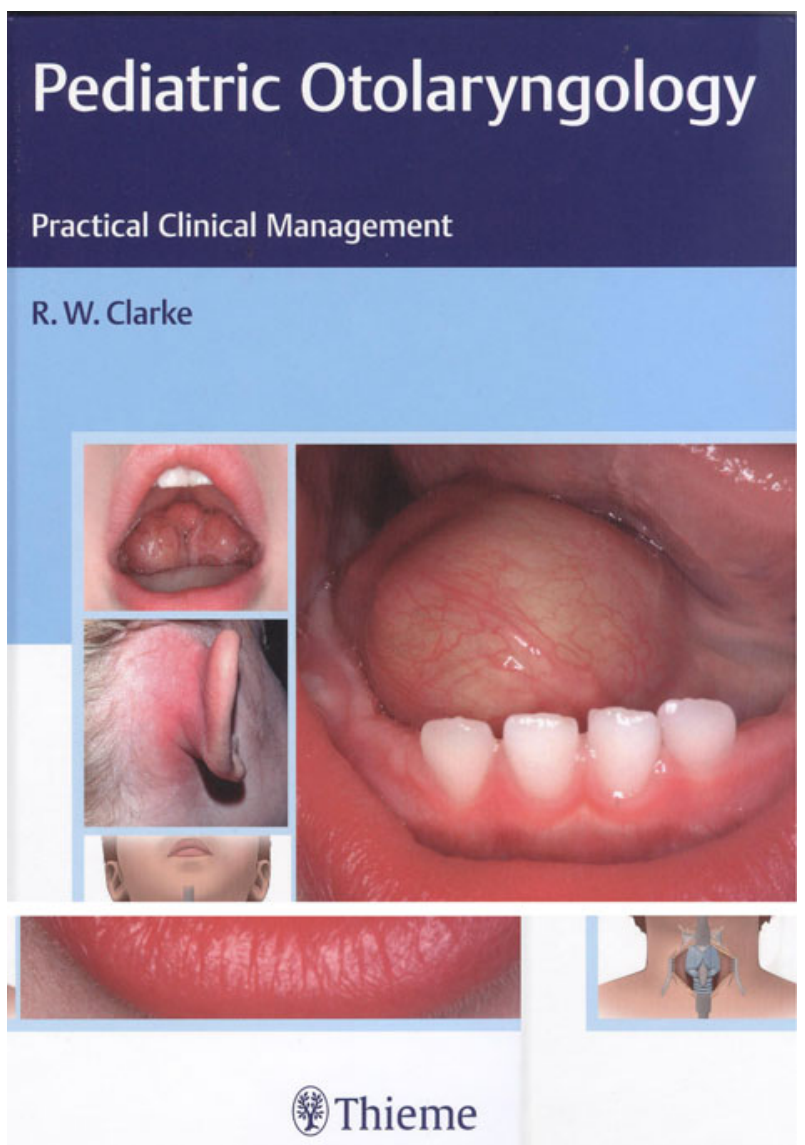

The 28 chapters are divided up into 6 sections: general considerations in children's ENT, the ear, the hearing impaired child, the nose and sinus, the airway, and the head and neck. The chapters separate out the congenital from acquired pathologies, and the common conditions are, appropriately, given more weight in the text. I particularly liked the inclusion of the multiple text boxes in each chapter, which contain 'tips and tricks', warning signs, surgical tips and other nuggets of information that make for an interesting read by themselves.

It is great to see recent landmark papers referenced (as recent as 2016) in a printed text, as so often it 
takes several years before a book finally comes to print. Another real credit to this book are the photographic and radiological illustrations. They are plentiful and of good quality. There are also multiple flow charts and diagrammatic illustrations, which are useful adjuncts to the text.

There are a few repetitions throughout the book, as a consequence of multiple authors, but no conflicting information. However, this doesn't detract from what is a good, comprehensive paediatric ENT text, suitable for trainees, particularly those preparing for exams, and practising ENT surgeons.

K BLACKMORE Middlesbrough, UK 